\title{
eCommons@AKU
}

March 2016

\section{Significance of Tumor Marker CA15-3 in Metastatic Breast Cancer}

Hoor Fatima

Jinnah Medical and Dental College, Karachi, Pakistan.

Amir Maqbool

Department of Oncology, Karachi Institute of Radiology and Nuclear Medicine, Karachi, Pakistan.

Marium Siddiqui

Baqai University, Karachi, Pakistan.

Ghulam H

Aga Khan University, ghulam.haider@aku.edu

Habiba Sohail

Jinnah Medical and Dental College, Karachi, Pakistan.

See next page for additional authors

Follow this and additional works at: http://ecommons.aku.edu/pakistan_fhs_mc_med_med Cart of the Oncology Commons

\section{Recommended Citation}

Fatima, H., Maqbool, A., Siddiqui, M., H, G., Sohail, H., Saleem, O., Ahmed, A. (2016). Significance of Tumor Marker CA15-3 in Metastatic Breast Cancer. Journal of Cancer and Tumor International., 4(3), 1-12.

Available at: http://ecommons.aku.edu/pakistan_fhs_mc_med_med/581 
Authors

Hoor Fatima, Amir Maqbool, Marium Siddiqui, Ghulam H, Habiba Sohail, Omema Saleem, and Afarina Ahmed 


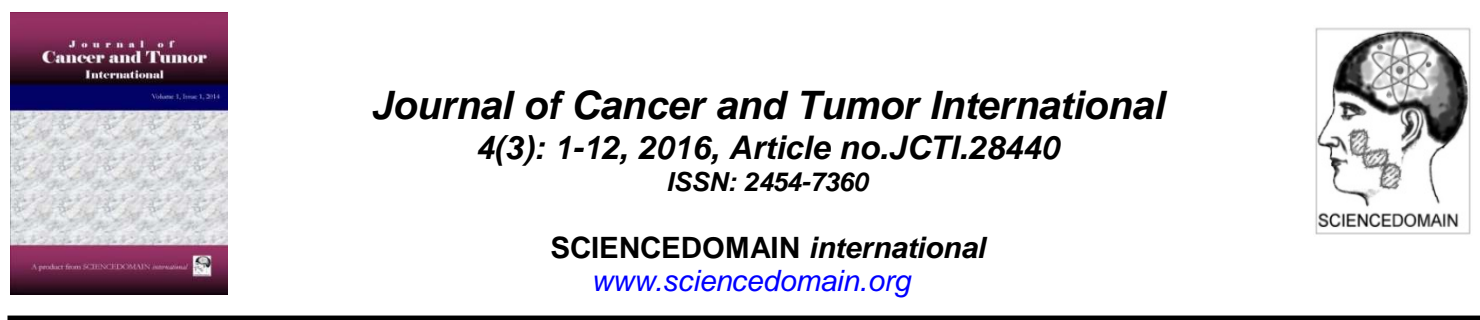

\title{
Significance of Tumor Marker CA15-3 in Metastatic Breast Cancer
}

\author{
Hoor Fatima $^{1^{*}}$, Amir Maqbool ${ }^{2}$, Marium Siddiqui ${ }^{3}$, Ghulam Haider ${ }^{4}$ \\ Habiba Sohail $^{1}$, Omema Saleem $^{5}$ and Afarina Ahmed ${ }^{6}$ \\ ${ }^{1}$ Jinnah Medical and Dental College, Karachi, Pakistan. \\ ${ }^{2}$ Department of Oncology, Karachi Institute of Radiology and Nuclear Medicine, Karachi, Pakistan. \\ ${ }^{3}$ Baqai University, Karachi, Pakistan. \\ ${ }^{4}$ Jinnah Post Graduate Medical Institute, Karachi, Pakistan. \\ ${ }^{5}$ Dow International University, Karachi, Pakistan. \\ ${ }^{6}$ Department of Community Medicine, Jinnah Medical and Dental College, Karachi, Pakistan.
}

Authors' contributions

This work was carried out in collaboration between all authors. Author HF designed the study and wrote the first draft of the manuscript. Author AM wrote the protocol. Author MS managed the literature searches. Author GH supervised the author HF to design the study and protocol writing. Author HS wrote the last draft of the manuscript. Author OS managed the experimental process. Author AA performed the statistical analyses of the study. All authors read and approved the final

manuscript.

Article Information

DOI: $10.9734 / \mathrm{JCTI} / 2016 / 28440$

Editor(s):

(1) William CS Cho, Queen Elizabeth Hospital, Hong Kong.

Reviewers:

(1) Ranniere Gurgel Furtado de Aquino, Universidade Federal do Ceará , Brazil

(2) Jyoti Bajpai, Tata memorial Hospital, Mumbai, India.

(3) Yu Koyama, Niigata University Graduate School of Health Sciences, Japan. Complete Peer review History: http://www.sciencedomain.org/review-history/16607

Original Research Article

Received $19^{\text {th }}$ July 2016 Accepted $8^{\text {th }}$ September 2016 Published $18^{\text {th }}$ October 2016

\section{ABSTRACT}

Secondary spread of cancer to bones is commonest and frequent phenomenon and enhances the need of special care for sufferers. Bone metastases mostly are the first complication of different variety of cancers which increase the need of care and expensive facilities. Blood dissemination is another common route, might be due to the venous drainage from visceral organs directly into the axial bones. CA 15-3 is a mucinous tumor markers derived from MUC1 gene, provides better guide line about the treatment, recurrence and prognosis.

Aim: Aim of the study was to signify the role of tumor marker CA15-3 in metastatic breast cancer.

*Corresponding author: Email: hoorimran@yahoo.com; 


\begin{abstract}
Methods: Hundred females of breast cancer (any age) with different stages of breast cancer with and without bone metastasis were tested for their serum level of CA 15-3 (biomarker of breast cancer). Bone scan was done to check the secondary metastasis to bones. Intravenous dye Ttechnicium 99 MDP has been used. Serum levels of ca15-3 were measured with the help of Gama Counter with computerized system and IRMA kit (Immunoradiometric Assay) by IMMUNOTECH. Ultrasound of whole abdomen and $\mathrm{X}$ ray/CT scan were used to detect liver and pulmonary metastasis respectively.

Results: Results indicate a high statistical significant relationship between bone metastasis and elevated levels of tumor marker CA 15-3 in breast cancer patients. Elevated levels of tumor marker CA 15-3 is strongly correlated with positive bone scan. An elevated level of tumor marker CA 15-3 is also correlated with positive pulmonary metastasis CA 15-3 is highly sensitive to detect bone metastasis and also sensitive to detect pulmonary metastasis. A lesser extent of high CA 15-3 serum levels is determinant of liver metastasis. Bone scan is essential tool to detect bone metastasis but need assistance of chemical biomarkers.

Conclusions: CA 15-3 as a tumor marker proved a help full determinant of tumor burden in metastatic breast cancer. Its significance is more to detect bone metastasis than to pulmonary and then to liver metastasis. Future studies upon CA15-3 in association with imaging techniques and other organ related specific tumor markers to detect specific metastasis or overall body tumor burden will be blessing for patients and physicians.
\end{abstract}

Keywords: Tumor marker CA15-3; bone; liver and lung metastasis; bone scan; breast cancer.

\section{INTRODUCTION}

Cancer is a main reason of mortality in developed and undeveloped countries. Main reasons are the raise in world population and aging especially in low socioeconomic countries which accounts up to $82 \%$ of the world's population. Estimated new female breast cancer cases by age in USA, 2015 were 60,290 of ductal carcinoma in situ and 231,840 of lobular carcinoma in situ. Total estimated deaths by age in USA 2015 were 40,290 [1]. According to collected data of 2012 about 14.1 million new cases and 8.2 million deaths occurred because of breast cancer. Lung and breast cancer are top most cancers that ultimately end on death in both genders worldwide [2]. Secondary spread of cancer to bones is commonest and frequent phenomenon and enhances the need of special care for sufferers $[3,4,5,6]$. Bone metastases mostly are the first complication of different variety of cancers which increase the need of care and expensive facilities. Different tumors have different specific sites of metastasis. [4 Metastasis up to bones and consecutive bone related complication like fracture, hypocalcaemia, pain and declines in mobility and performance status are common in breast cancer, prostate cancer and multiple myeloma [5,6,7]]. The disease stage and the biological properties of the tumor are the basis of secondary metastasis. Influencing prognostic factors for the recurrence of cancer are the size of the tumor, nodal involvement, presence of lymphovascular and perineural invasion, tumor grade, receptor status of hormones like estrogen and progesterone, and HER2 (human epidermal growth factor receptor2). Metastatic breast tumors to different organs represent heterogeneous characteristics and biological behavior. A recent study shows that the hormone receptor and HER2 positivity or negativity, site of the metastasis (visceral vs. non-visceral), performance status, disease-free survival period, initial adjuvant treatment and the initial treatment given to the patients of secondary metastatic breast cancer are the factors that influence the outcome [8].

Most affected site is the axial skeleton secondary to breast cancer. Blood dissemination is another common route, might be due to the venous drainage from visceral organs directly into the axial bones. According to postmortem research on animals and humans by Batson [9] confirmed that venous blood from the breasts and pelvic organs, like the prostate, drained into the vena cava, and vertebral-venous (Batson's) plexus of vessels as well, from the pelvis up to the epidural and perivertebral veins. Direct extension of vascular routes from viscera to axial skeleton describes the involvement of axial skeleton in breast and prostate cancers. Structural interaction between cells, molecules and chemicals of bones are responsible for cancer growth within bones. $[10,11]$ Bone scintigraphy with technetium-99 m-labeled diphosphonates is a commonest radionuclide procedure which is not only specific but also sensitive that is why 
used as a screening tool for many pathologic conditions. Some pathological conditions which cannot pick by other imaging techniques can be diagnosed with bone scan. Secondary Bone metastases showed as hot spots but some times less echogenic. Other bone injuries can be detected, in the absence of other radiographic findings. Bone fractures can be detected by bone scan within 24 hours, except osteopenia in older patients [12]. About $75 \%$ symptomatic malignant cases easily detected by bone scintigraphy but $25 \%-45 \%$ of asymptomatic patients with malignancy also have positive bone scan for metastases $[13,14,15]$. Result of a study showed that breast cancer with multiple bone metastases is associated with advanced staging. Patients with concurrent lesions of rib and other sites had a significantly higher rate of metastatic disease than those with only other site lesions. Rib metastasis incidences were higher in cases with multiple rib lesions, lymph node metastasis, and lesions of both ribs. [16] Use of tumor markers is success full molecular tools to defining early diagnosis, prognosis, and treatment plan [17]. CA 15-3, CA 459 etc are mucinous tumor markers derived from MUC1 gene, and are useful as diagnostic tumor markers in cancer. [18] (Kufe, 2012). Clinically they provide better guide line about the treatment and prognosis. CA 15-3 consists of 3 domains and 2 subunits. The extracellular subunit contains 20 amino acid residues. Subunits of CA 15-3 contain functional site and important in evaluation of significance of CA 15-3 in breast cancer $[19,20,21]$. Higher values of CEA and CA 15-3 found before surgery showed higher mortality, $(P=0.0001$ for both markers). A decline of CA 15-3 of more than 33\% was also associated with worst outcome which might be recurrence or death (death from disease $P=0.007$; disease free survival $\mathrm{P}=0.0087$ ). Comparatively CA $15-3$, the CEA decline alone, independent of levels before surgery was strong indicator of recurrence and mortality [22]. Elevated CA 15-3 level indicates that treatment regimen is not suitable. CA $15-3$ is a serum based and noninvasive test and easy to perform. Kurebayashi et al. [23] stated that higher levels of ca15-3 before start of treatment and change in post therapy levels linked with prognosis. CA 15-3 values predicts the outcome of disease and treatment [24]. Role of CA15-3 as a marker at molecular and pathological level and its significance to determine response of treatment as well as chances of recurrence need further work. In a recent review Duffy et al. [25] decided that in advanced stages CA15-3 is essential to check response of treatment. Expert panels like NACB and EGTM emphasize to check CA 15-3 level in monitoring treatment response $[26,27]$. Otherwise ASCO panel do not think it is as an important diagnostic and prognostic tool.

Aim of the study was to signify the role of tumor marker ca15-3 in metastatic breast cancer.

\section{METHODOLOGY}

\subsection{Selection of Patients}

Data were collected by trained medical physician, nurses and laboratory persons. General information from each subject was collected through a standard questionnaire including participant's name, age, education, monthly income and living style, ethnicity, gravidity, para, abortions, clinical sign and symptoms, material status, family history, etc. We explained the objectives and important features of the study to all patients prior to the start of study and their consent was taken.

\subsection{Blood Collection}

Before interviewing and blood collection a verbal consent was taken from each respondent. Venous blood was withdrawn for the investigation. First the skin was cleaned thoroughly with sterilized with $70 \%$ Isopropyl Alcohol swab and dried before puncturing. $2 \mathrm{ml}$ of blood taken from the antecubital vein by using $5 \mathrm{cc}$ disposable syringe (Becton Dickinson, PAK PVT Ltd). The blood sample was transferred to labeled test tube. And then tubes were marked with codes and immediately taken to the lab.

\subsection{Inclusion Criteria}

Hundred females of breast cancer (any age) with different stages of breast cancer with and without bone metastasis were tested for their serum level of CA 15-3 (biomarker of breast cancer). Bone scan was done to check the secondary metastasis to bones. During the study Chemo therapy and radiotherapy were allowed accordingly and most of patients have passed through the first three cycles of chemotherapy and radiotherapy.

\subsection{Exclusion Criteria}

All the known cases of primary bone diseases, lung diseases and liver diseases were excluded from study. 


\subsection{Bone Scan}

Bone scan was done on Siemen E Cam scanner with accessories. (Figs. 1A \& B) Intravenous dye Ttechnicium 99 MDP has been used. This test helps to see if a cancer has metastasized to bones and is useful because it provides a picture of the entire skeleton. For this purpose, $20 / \mathrm{mci}$ (dose) of radioactive material (technetium 99) was injected into a vein (intravenously or IV). The substance settles in areas of damaged bone throughout the entire skeleton over the course of a couple of hours. (Six hours to twenty four hours). Patient lied on a table for about 30 minutes while a special camera detected the radioactivity and created a picture of the skeleton.

\subsection{Ultraosund}

Simple Grey scale ultrasound was done on Toshiba machine model no Aplio 500.

\subsection{Ray /CT Scan Chest}

X ray done on $14 \times 17$ Samsung Flat Panel X-Ray machine.

CT scan chest done on Toshiba Aquilion 8.

\subsection{Biochemical Parametre}

\subsubsection{CA15-3}

Serum levels of ca15-3 were measured with the help of Gama Counter (Fig. 1C) with computerized system and IRMA kit (Immunoradiometric Assay) by IMMUNOTECH, REF, and IRMA 2397. We collected the serum in simple tubes and stored at $<-18$ degree centigrade. First diluted the samples and control by adding 10/up of samples or control in to glass tubes and then adding to each tube 500/ul of diluents and then shaken gently before use. To coated tubes we added 200/up of calibrator, of diluted sample or of diluted control then incubated for two hrs at 18- 25 degree centigrade with shaking at $400 \mathrm{rpm}$. Then aspirated the content of each tube, then washed twice with $2 / \mathrm{ml}$ of distilled water. After that we carefully aspirated. After aspiration we added 200/ul of tracer in each tube, incubated for $1 \mathrm{hr}$ at 18-25 /degree centigrade with shaking at $400 \mathrm{rpm}$. For counting the bind antigen antibody, aspirated the content of each tube, then washed twice with $2 / \mathrm{ml}$ of distilled water. Then counted for 1 minute both bound B cpm and total cpm. We also added the $200 /$ ul of tracer in 2 additional tubes to obtain total cpm.
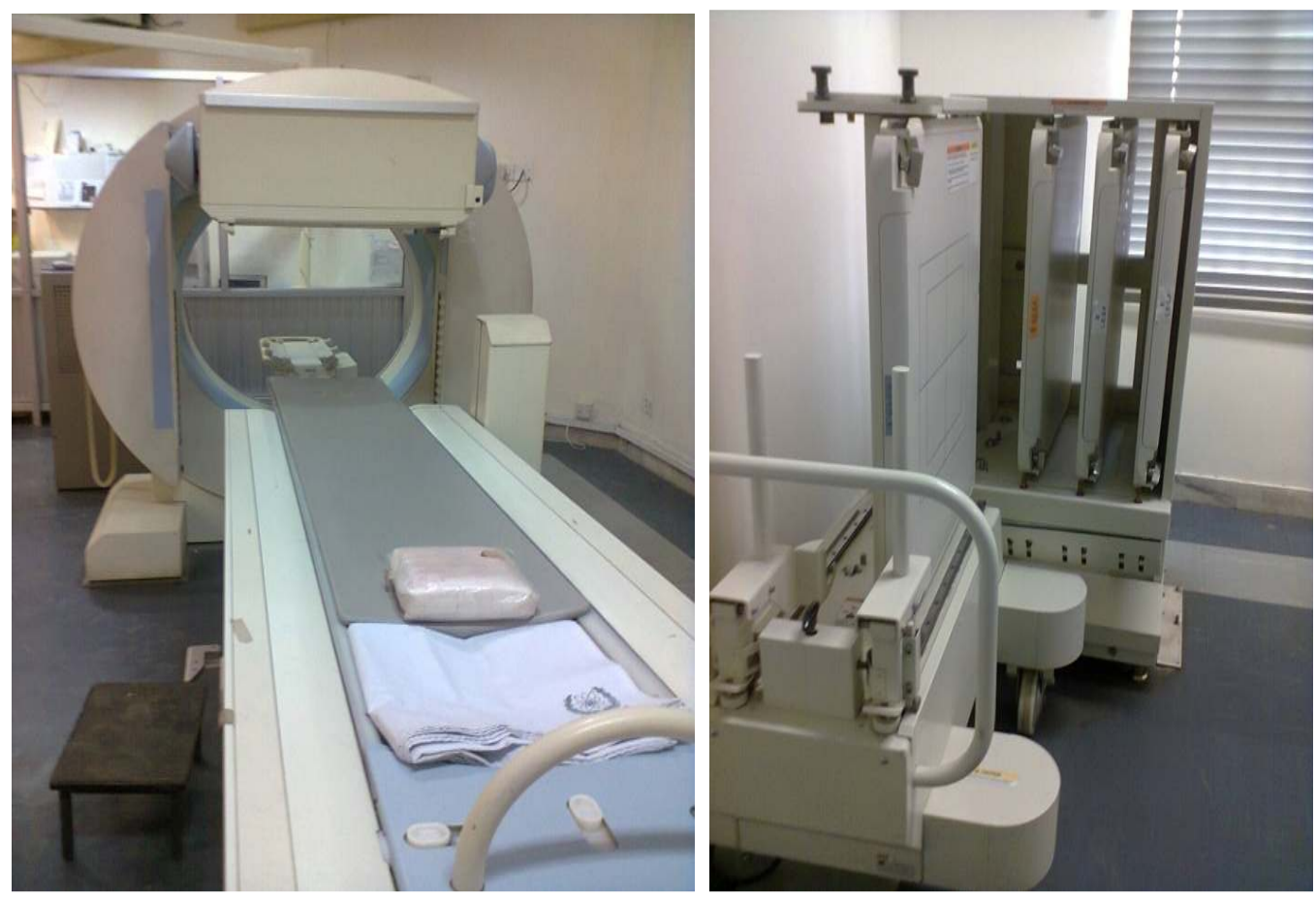

Fig. 1A \& B. Siemens E Cam Bone Scan Machine with the permission of Kiran Hospital, Karachi 


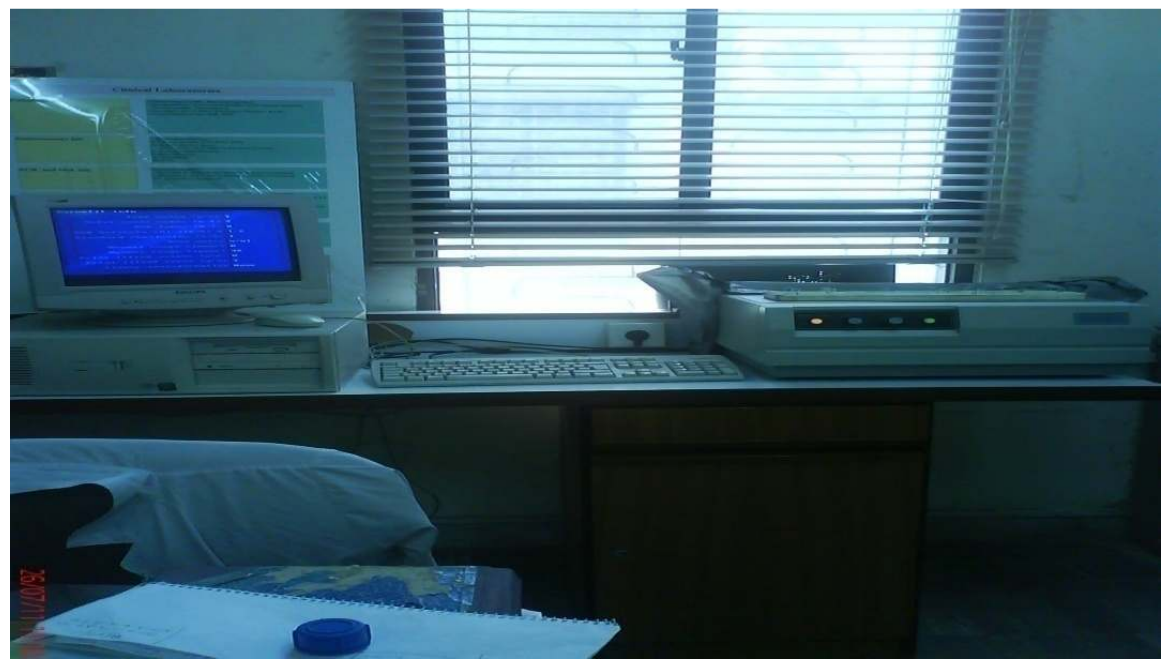

Fig. 1C. Gamma Counter with coputerized system for the assay analysis of CA15-3. With the permission of KIRAN hospital, karachi

\subsection{Statistical Analysis}

The data feeding and analysis was done on computer package SPSS (Statistical Packages of Social Sciences) version 11.0. Clinical characteristics will be summarized in terms of mean \pm S.D, SEM, for quantitative variable. Student t-test was used for comparison of quantitative variables in between bone scanning positive and negative groups. For statistical analysis only $p$-value $<0.05$ are considered significant.

\section{RESULTS}

Comparison of general characteristics age, marital status and parity showed no statistical significant analysis among bone scan positive and negative groups [Table 1]. Analysis of TNM staging in bone scan positive group showed maximum cases of $\mathrm{t} 4 \mathrm{n} 1 \mathrm{~m} 1$ and $\mathrm{t} 1 \mathrm{n} 0 \mathrm{~m} 0$ which are 13 in number then stage $t 3 n 1 \mathrm{~m} 1$ was predominant, 11 cases and then $\mathrm{t} 2 \mathrm{n} \times \mathrm{m} 0$ (8). None of stage t $1 \mathrm{nxm} 0, \mathrm{t} 2 \mathrm{n} 2 \mathrm{~m} 0, \mathrm{t} 2 \mathrm{n} 3 \mathrm{mx}, \mathrm{t} 3 \mathrm{n} 2 \mathrm{~m} 0$, t $3 n 2 m x$ related case was found. Among bone scan negative cases maximum cases of stage $\mathrm{t} 2 \mathrm{n} 0 \mathrm{~m} 0$ (14) and then stages $\mathrm{t} 2 \mathrm{n} 0 \mathrm{~m} 0, \mathrm{t} 1 \mathrm{n} 1 \mathrm{~m} 0$ (9, 8) were found. No case of stage $44 \mathrm{n} 1 \mathrm{~m} 1$ was found [Table 2].

A highly significant relationship was found between bone metastasis and elevated levels of tumor marker CA 15-3 in serum of breast cancer patients. Results are statistical significant. Serum CA 15-3 levels are remarkably high in cases with age group below 30 and above 70 years. Paired with bone scan CA 15-3 levels confirms the bone metastasis in breast cancer patients. Moderate increase of CA 15-3 levels were found in perimenopausal and menopausal patients (40-69 years). Age group of (30-39 years showed slight lower tendency of bone metastasis and increase in serum CA 15-3 levels). Some cases of breast cancer without bone metastasis also showed high serum levels of tumor marker CA 15-3 which is statistical insignificant [Table 3]. Number of Liver and Lung metastasis were more or less same among bone scan positive and negative groups and were not statistically significant. $\mathrm{P}$ value for liver metastasis was near to significant level (0.06) [Table 4]. CA15-3 serum levels found higher in positive liver metastasis patients among both groups of bone scan. $P$ value (.098) is near the level of statistical significance [Table 5]. A statistical significant relationship was found between bone metastasis and elevated levels of tumor marker CA 15-3 in serum of breast cancer patients, $P$ value $(.016)$ [Table 6].

\section{DISCUSSION}

Cancer is the worldwide growing menace for health and responsible for death as a second number killer. The incidence rate of mortality in developed and underdeveloped countries is more or less same or still increasing. Reason may be the increase life span and common exposure to risk factors [28]. Globally Breast cancer is counted as commonest cancer and having more than $1,300,000$ new cases and 450,000 demises every year worldwide [29]. 
Table 1. General characteristic

\begin{tabular}{|c|c|c|c|}
\hline & \multicolumn{2}{|c|}{ Bone scanning } & \multirow[t]{2}{*}{ P-value } \\
\hline & $\begin{array}{l}\text { Positive } \\
(n=100)\end{array}$ & $\begin{array}{l}\text { Negative } \\
(n=100)\end{array}$ & \\
\hline \multicolumn{4}{|l|}{ Age in years } \\
\hline Under 30 & 8 & 5 & 0.732 \\
\hline $30-39$ & 20 & 21 & \\
\hline $40-49$ & 32 & 35 & \\
\hline $50-59$ & 22 & 27 & \\
\hline $60-69$ & 12 & 9 & \\
\hline 70 \& above & 6 & 3 & \\
\hline $\begin{array}{l}\text { Mean } \pm S . D \pm S E M \\
\text { Marital status }\end{array}$ & $46.7 \pm 12.49 \pm 1.26$ & $46.1 \pm 10.47 \pm 1.26$ & 0.733 \\
\hline Married & 94 & 96 & 0.516 \\
\hline Unmarried & 6 & 4 & \\
\hline \multicolumn{4}{|l|}{ Parity } \\
\hline \multicolumn{4}{|l|}{ Alive children } \\
\hline None & 14 & 7 & \\
\hline $1-3$ & 23 & 27 & 0.209 \\
\hline $4-6$ & 40 & 49 & \\
\hline 7 \& above & 23 & 17 & \\
\hline \multicolumn{4}{|l|}{ Abortion } \\
\hline None & 59 & 59 & \\
\hline 1 & 21 & 29 & 0.320 \\
\hline 2 & 15 & 11 & \\
\hline 3 & 5 & 1 & \\
\hline
\end{tabular}

In 2012, I, 52,680 new cases of breast cancer is supposed to report and an expected risk of 52 cases out of 100,000 women [30]. Prevalence and mortality rate is higher in growing age group. $50 \%$ percent of half of the females with age of 65 and onward die because of breast cancer [31]. If the patient survives breast cancer can lead to severe illness causes and even permanent disabilities. Aggressive behavior of cancer tissues may lead to a decrease in life expectancy [32].

During our study CA15-3 serum level was found significantly high in bone scan positive cases especially cases with advance staging, $P$, value is statistically significant, $P<0.01$. Serum levels of CA 15-3 were found high also in some negative cases of bone metastasis which was not statistically significant, but important from the morbidity point of view. Comparison of serum levels of CA 15-3 in patients of different age group with and without bone metastasis showed that extreme of age (under $30 \&$ above 70 years shows) greater tendency of bone metastasis and related morbidity. Moderate increase of CA 15-3 levels were found in perimenopausal and menopausal patients (40-69 years). Age group of (30-39 years shows slight lower tendency of bone metastasis and increase in serum CA 15-3 levels). Lung and liver metastasis is common in breast cancer. Number of Liver and Lung metastasis were same among bone scan positive (22) and negative groups (12 and 14 respectively). $\mathrm{P}$ value for liver metastasis was near to significant level (0.06). CA15-3 serum levels found higher in positive liver metastasis patients among both groups of bone scan. $\mathrm{P}$ value (.098) is near the level of statistical significance. A statistical significant relationship was found between lung metastasis and elevated levels of tumor marker CA 15-3 in serum of breast cancer patients, $P$ value (.016). Study provides that in breast cancer bones are commonest sit of metastasis then lung and then liver. Raised CA 15-3 levels in serum of patients can predict the metastasis to these sites.

A comparative study regarding the sites of breast cancer metastasis declares the longer survival period for bone and lung metastasis patients than liver metastasis. Brain metastasis showed least survival period. Post-menopause, diabetes 
mellitus, lymphovascular invasion positivity, high disease grade, and multiple organ metastases are related to poor disease out come. Bone only spread of cancer is appeared a better predictor of survival. Lungs are also a second common site of breast cancer metastasis [33]. 1Radiation Oncology Department, Cumhuriyet University School of Medicine, Sivas, TR-58140, Turkey 2Medical Oncology Department, Cumhuriyet University School of Medicine, Sivas, TR-58140, TurkeyAustin J Med Oncol - Volume 1 Issue 2 2014.

\section{Table 2. TNM staging in bone scan positive} and negative cases of breast cancer

\begin{tabular}{|c|c|c|c|}
\hline \multicolumn{2}{|c|}{$\begin{array}{l}\text { TNM staging in bone } \\
\text { scan positive cases }\end{array}$} & \multicolumn{2}{|c|}{$\begin{array}{l}\text { TNM staging in bone } \\
\text { scan negative cases }\end{array}$} \\
\hline t1n0m0 & 13 & t1m0n0 & 9 \\
\hline $\mathrm{t} 1 \mathrm{n} 1 \mathrm{~m} 0$ & 4 & $\mathrm{t} 1 \mathrm{n} 1 \mathrm{~m} 0$ & 8 \\
\hline t1nxm0 & 0 & t1nxm0 & 4 \\
\hline $\mathrm{t} 2 \mathrm{n} 0 \mathrm{~m} 0$ & 8 & $\mathrm{t} 2 \mathrm{n} 0 \mathrm{~m} 0$ & 14 \\
\hline t1nxm0 & 4 & t $1 \mathrm{n} \times \mathrm{m} 0$ & 1 \\
\hline $\mathrm{t} 2 \mathrm{n} 1 \mathrm{mx}$ & 5 & $\mathrm{t} 2 \mathrm{n} 1 \mathrm{mx}$ & 1 \\
\hline $\mathrm{t} 2 \mathrm{n} 1 \mathrm{~m} 0$ & 4 & $\mathrm{t} 2 \mathrm{n} 1 \mathrm{~m} 0$ & 4 \\
\hline $\mathrm{t} 2 \mathrm{n} 2 \mathrm{~m} 0$ & 0 & $\mathrm{t} 2 \mathrm{n} 2 \mathrm{~m} 0$ & 4 \\
\hline t2n2mx & 1 & $\mathrm{t} 2 \mathrm{n} 2 \mathrm{mx}$ & 2 \\
\hline t2n3mx & 0 & t2n3mx & 2 \\
\hline $\mathrm{t} 2 \mathrm{n} \times \mathrm{m} 0$ & 8 & t2nxm0 & 4 \\
\hline t2nxmx & 1 & t2nxmx & 2 \\
\hline $\mathrm{t} 3 \mathrm{n} 1 \mathrm{~m} 1$ & 11 & $\mathrm{t} 3 \mathrm{n} 1 \mathrm{~m} 1$ & 4 \\
\hline $\mathrm{t} 3 \mathrm{n} 1 \mathrm{mx}$ & 2 & $\mathrm{t} 3 \mathrm{n} 1 \mathrm{mx}$ & 4 \\
\hline $\mathrm{t} 3 \mathrm{n} 2 \mathrm{~m} 0$ & 0 & $\mathrm{t} 3 \mathrm{n} 2 \mathrm{~m} 0$ & 2 \\
\hline $\mathrm{t} 3 \mathrm{n} 2 \mathrm{~m} 1$ & 1 & $\mathrm{t} 3 \mathrm{n} 2 \mathrm{~m} 1$ & 2 \\
\hline t3n2mx & 0 & t $3 n 2 m x$ & 2 \\
\hline t3nxmx & 4 & t3nxmx & 2 \\
\hline $\mathrm{t} 4 \mathrm{n} 1 \mathrm{~m} 1$ & 13 & $\mathrm{t} 4 \mathrm{n} 1 \mathrm{~m} 1$ & 0 \\
\hline $\mathrm{t} 4 \mathrm{n} 1 \mathrm{mx}$ & 2 & $\mathrm{t} 4 \mathrm{n} 1 \mathrm{mx}$ & 2 \\
\hline $\mathrm{t} 4 \mathrm{n} 2 \mathrm{~m} 1$ & 3 & $\mathrm{t} 4 \mathrm{n} 2 \mathrm{~m} 1$ & 2 \\
\hline
\end{tabular}

Increased serum CA 15-3 levels in advanced stages indicates its role as a prognostic marker as well. CA 15-3 is transmembrane protein and derived from MUC- 1, gene exists as a dimmer of two subunits. Two proteases, ADAM17, and MTMMP1 are responsible for hydrolysis [34,35]. Its expression is different on surface of different cell types, but it is over expression is seen in $90 \%$ cases of breast cancer [36]. An increase in CA 15-3 serum levels before surgery is strongly suggestive of relapse and demise. Different study plans are need of time to establish the prognostic role of CA 15-3 before surgery in cases of breast cancer. If it proved as an established prognostic tumor marker, then it must be a part of investigation prior to select the treatment regimen [37]. There are many risk factors which facilitates breast cancer. Elevated serum CA 15-3 levels and misbalance of ER, PR and Her2/NEU are thought to be main causative factors of breast cancer. The hormonal misbalance may be responsible for aggressive uncontrolled cell division. Alteration in active site of hormones in combination with interaction of extra cellular domain of CA 15-3 with a domain of ER may be responsible for metastasis in breast cancer through stimulation of RAS protein Pathway [38]. Elevated CA 15-3 serum level at $\mathrm{PC}$ and late tumor stage indicate a failure of response to chemotherapy. There is an inverse relation between CA15-3 level and response to chemotherapy, tumor size and lymphovascular spread. Kurebayashi et al. [39] proved that more than $20 \%$ post chemotherapy decrease in CA $15-$ 3 levels is an indicator of good prognosis and lessen the disease progression duration. Raised CA 15-3 levels shows bed prognosis after initial cycles of chemotherapy in breast cancer with local invasion. Simultaneous increase in CA15-3 levels after chemotherapy and presence of HER 2 receptors with local lymphovascular involvement is indicating greater morbidity [40]. A study upon comparison of different tumor markers such as CEA, Ca15.3, lactate dehydrogenase and CA 15-3 to analyze their combine and alone prognostic and predictive values showed that CA15-3 alone has an established role as a prognostic tumor marker. Role of other markers like CEA and LDH were fluctuating among different patients in metastatic breast cancer. Research also had the objective to assess the effect of high levels of tumor marker on survival duration. Raised levels of CA 15-3 were found to be a prognostic factor affecting survival duration [41].

Another research regarding the significance of CA15-3 in recurrence of breast cancer was showed that it was elevated in approximately half of bone-only metastases and in all of the liver-only metastases. In the pulmonary-only recurrences, the marker value was not elevated [42]. A multivariate analytical study to detect prognostic significance of CA15-3 and CA-125 in metastatic breast cancer proved the CA 15-3 and CA-125 powerful prognostic factor and indicator of visceral metastasis in advance stages of breast cancer [43].

Our study signifies the role of bone scintigraphy for detection of bone metastasis in combination with tumor marker CA 15 -3. Results showed that patients with positive bone scan were at advance stages of disease. 


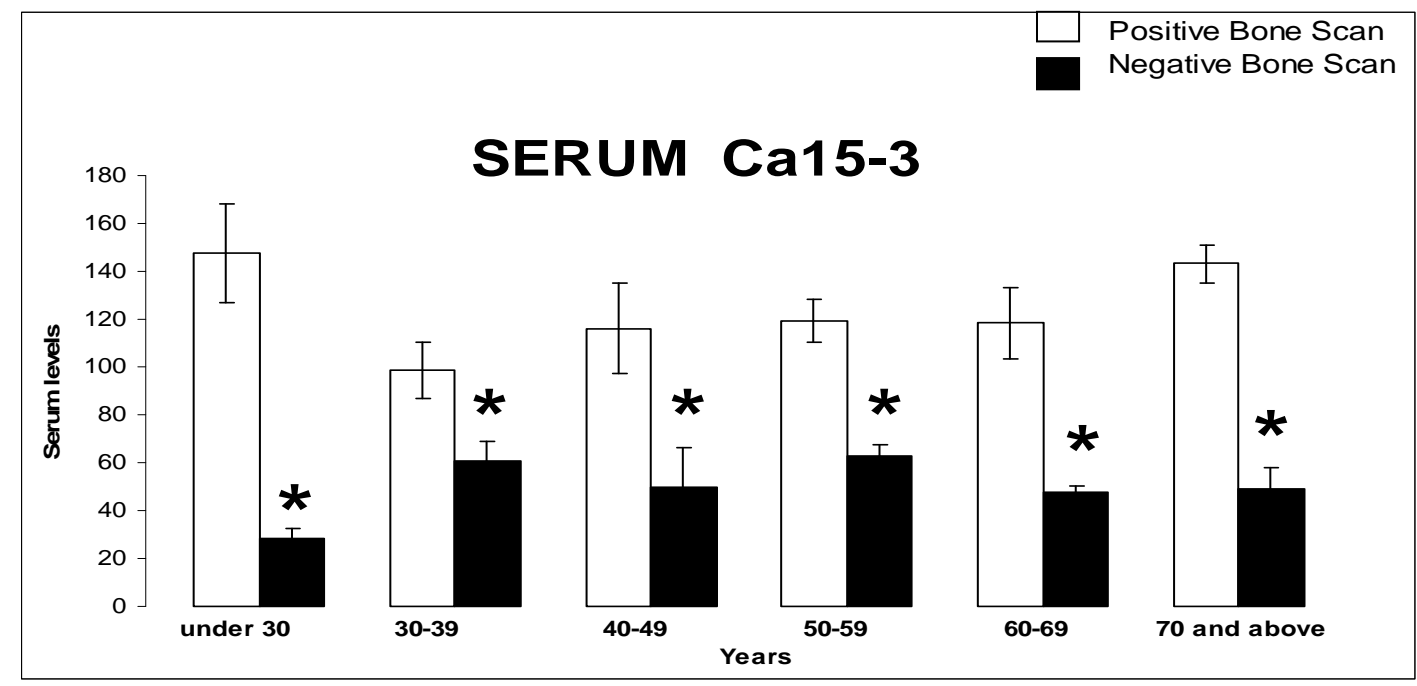

Fig. 2. Serum CA15-3 levels in subjects with positive- and negative bone scan

Fig shows comparison of serum Ca15-3 levels in the subjects of different age groups with positive and negative bone scan. Comparison showed significantly increased serum Ca15-3 levels in positive bone scan subjects as compared to negative bone scan group.

Statistically Significant. ${ }^{*} P<0.01$

Table 3. Biochemical parameter in bone scanning positive and negative case

\begin{tabular}{llllllll}
\hline $\begin{array}{l}\text { Biochemical } \\
\text { tumor marker }\end{array}$ & \multicolumn{3}{c}{$\begin{array}{c}\text { Bone scanning (Positive) } \\
(\mathbf{n}=\mathbf{1 0 0 )}\end{array}$} & \multicolumn{3}{c}{$\begin{array}{c}\text { Bone scanning (Negative) } \\
(\mathbf{n}=\mathbf{1 0 0 )}\end{array}$} & P value \\
\cline { 2 - 7 } & Mean & S.D & SEM & Mean & S.D & SEM & \\
\hline CA 15-3 & 127.2 & 151.16 & 15.19 & 54.1 & 71.97 & 7.23 & 0.001 \\
\hline
\end{tabular}

Table 4. Physical parameter in bone scanning positive and negative case

\begin{tabular}{llll}
\hline & \multicolumn{2}{c}{ Bone scanning } & P-value \\
\cline { 2 - 3 } & $\begin{array}{l}\text { Positive } \\
(\mathbf{n}=\mathbf{1 0 0})\end{array}$ & $\begin{array}{l}\text { Negative } \\
(\mathbf{n}=\mathbf{1 0 0})\end{array}$ & \\
\hline Liver & 22 & 12 & 0.060 \\
metastasis & & 14 & 0.141 \\
$\begin{array}{l}\text { Pulmonary } \\
\text { metastasis }\end{array}$ & 22 & 12 & \\
\hline \multicolumn{3}{c}{${ }^{* *}$ Statistically Significant $p<0.01$}
\end{tabular}

According to the NCCN clinical practice guidelines in oncology for breast cancer, international guidelines for management of metastatic breast cancer from the European School of Oncology (ESO)-MBC Task Force [40], as well as earlier studies $[44,45,46,47,48]$ Confirmatory Imaging techniques secondary to bone metastasis are CT or MRI. Hot spots on bone scan are supposed the benign lesions by physicians and no need of other imaging techniques. Patient should be keep on only on followed up. If there is any suspicion of metastatic disease on bone scan, CT, MRI, PET scans are the appropriate choices. Majority of bone scans are performed with intention to detect malignancy, especially in malignancies of the breast, prostate gland, and lung. Bone imaging modalities are important for cancer histopathological staging and management. This technique is useful to pick skeletal abnormalities, and numerous studies have confirmed that it is considerably more sensitive than conventional radiography for this purpose. [49,50,51,52]. About $75 \%$ of patients with malignancy and pain have abnormal bone scintigraphic findings. Perhaps even more importantly, $25 \%-45 \%$ of asymptomatic patients with malignancy have scintigraphic evidence of bone metastases. The usual pattern consists of increased radiotracer deposition in areas of osteoblastic reparative activity in response to tumor osteolysis $[53,54,55]$. Bone scintigraphy is a popular and important imaging modality and will likely remain so for the foreseeable future. Although bone scintigraphy is not specific, its exquisite sensitivity makes it a useful screening procedure 
Table 5. Biochemical parameter in bone scanning positive and negative case

\begin{tabular}{|c|c|c|c|c|c|c|c|}
\hline \multirow[t]{3}{*}{$\begin{array}{l}\text { Biochemical } \\
\text { tumor marker }\end{array}$} & \multirow{2}{*}{\multicolumn{3}{|c|}{$\begin{array}{c}\text { Bone scanning (Positive) } \\
(n=100) \\
\text { Liver metastasis positive } \\
n=22\end{array}$}} & \multirow{2}{*}{\multicolumn{3}{|c|}{$\begin{array}{c}\text { Bone scanning (Negative) } \\
(\mathrm{n}=100) \\
\text { Liver metastasis positive } \\
\mathrm{n}=12\end{array}$}} & \multirow[t]{3}{*}{$P$ value } \\
\hline & & & & & & & \\
\hline & Mean & S.D & SEM & Mean & S.D & SEM & \\
\hline CA 15-3 & 127.48 & 139.11 & 1.39 & 161.39 & 148.60 & 1.48 & 0.0985 \\
\hline
\end{tabular}

Table 6. Biochemical parameter in bone scanning positive and negative case with positive pulmonary metastasis

\begin{tabular}{|c|c|c|c|c|c|c|c|}
\hline \multirow[t]{3}{*}{$\begin{array}{l}\text { Biochemical } \\
\text { tumor marker }\end{array}$} & \multicolumn{3}{|c|}{$\begin{array}{l}\text { Bone scanning (Positive) } \\
(\mathrm{n}=100)\end{array}$} & \multicolumn{3}{|c|}{$\begin{array}{c}\text { Bone scanning (Negative) } \\
(n=100)\end{array}$} & \multirow[t]{3}{*}{$P$ value } \\
\hline & \multicolumn{3}{|c|}{$\begin{array}{l}\text { Pulmonary metastasis positive } \\
n=22\end{array}$} & \multicolumn{3}{|c|}{$\begin{array}{l}\text { Pulmonary metastasis positive } \\
n=14\end{array}$} & \\
\hline & Mean & S.D & SEM & Mean & S.D & SEM & \\
\hline CA 15-3 & 145.08 & 83.8 & 0.83 & 51.76 & 375.50 & 0.37 & 0.0162 \\
\hline
\end{tabular}

for many pathologic conditions. Moreover, some conditions that are not evident on anatomic images can be diagnosed with radionuclide bone imaging [56].

\section{CONCLUSIONS}

Elevated levels of tumor marker CA $15-3$ is strongly correlated with positive bone scan.

Bone scan is highly sensitive to detect bone metastasis but need assistance of chemical biomarkers.

CA 15-3 as a tumor marker proved a help full determinant of tumor burden in metastatic breast cancer. Its significance is more to detect bone metastasis than to pulmonary and then to liver metastasis.

\section{CONSENT AND ETHICAL APPROVAL}

It is clinical study and no animals are involved. Informed consent has been taken from each participant. Aims and procedure of experiment has been described. All authors hereby declare that all experiments have been examined and approved by ethical committee of Board of Advanced Study and Research of Karachi University.

\section{COMPETING INTERESTS}

Authors have declared that no competing interests exist.

\section{REFERENCES}

1. Rick A, Tracie Bertaut, Louise A. Brinton, Stacey Fedewa, Rachel, Jiaquan Xu, et al. Breast cancer facts \& figures. American Cancer Society, 250 Williams Street, NW, Atlanta, GA 30303-100; 2015-2016.

2. Lindsey A. Torre, Freddie Bray, Rebecca L. Siegel, Jacques Ferlay, Joannie LortetTieulent, Ahmedin Jemal DVM. Global Cancer Statistics, 2012 CA Cancer J Clin. 2015;65:87-108.

3. Roodman GD. Mechanisms of bone metastasis. $\mathrm{N}$ Engl $\mathrm{J}$ Med. 2004;350:1655-1664.

[PubMed: 15084698]

4. Coleman RE. Bisphosphonates. Clinical experience. Oncologist. 2004;9(Suppl 4): 14-27.

[PubMed: 15459426]

5. Fidler IJ. Cancer metastasis. Br Med Bull. 1991;47:157-177.

[PubMed: 1863845]

6. Mohler J, Amling CL, Bahnson RR, et al. NCCN clinical practice guidelines in oncology: Prostate cancer, v.2; 2009.

Available:http://www.nccn.org/professional s/physician gls/PDF/prostate.pdf

[Accessed May 21, 2009]

7. Carlson RW, Allred DC, Anderson BO, et al. NCCN clinical practice guidelines in oncology: Breast cancer, v.1; 2009.

[Accessed May 21, 2009]

8. Beslija S, Bonneterre J, Burstein HJ. Third consensus on medical treatment of 
metastatic breast cancer. Ann Oncol. 2009;20:1771-1785.

9. Batson O. The role of vertebral veins in metastatic processes. Ann Intern Med. 1942;16:38-45.

10. Charito Love, Anabella S. Din, Maria B. Tomas, Tomy P. Kalapparambath, Christopher J. Palestro. Radionuclide bone imaging: An illustrative review. 2003;23(2): 342.

11. Hage WD, Aboulafia AJ, Aboulafia DM. Incidence, location, and diagnostic evaluation of metastatic bone disease. Orthop Clin North Am. 2000;31:515-528.

12. Palmer E, Henrikson B, McKusick K, Strauss HW, Hochberg F. Pain as an indicator of bone metastasis. Acta Radiol. 1988;29:445-449.

13. Bibbo C, Patel DV, Benevenia J. Perioperative considerations in patients with metastatic bone disease. Orthop Clin North Am. 2000;31:577-595.

14. Qin Li, Zhiqiang Chen, Yansheng Zhao, Xiuqing Li, Hong Pan, Tiansong Xia, Lin Chen, Zhaogiang $\mathrm{Xu}$, Wenbin Zhou, Xiaoan Liu. Risk of metastasis among rib abnormalities on bone scans in breast cancer patients. Scientific Reports. 2015;5: 9587.

DOI: $10.1038 /$ srep09587

15. Tsuda $\mathrm{H}$. Accumulation of gene alterations and progression of breast cancer. Gan To Kagaku Ryoho. 1994;21:172-7.

16. Molecular biomarkers for breast cancer prognosis: Coexpression of c-erbB-2 and p53. Ann Surg. 2001;233:630-8.

17. Kufe DW. MUC1-C oncoprotein as a target in breast cancer: Activation of signaling pathways and therapeutic approaches. Oncogene; 2012.

DOI: 10.1038/onc.2012.158

[Epub ahead of print].

18. Jiang $X P$, Yang DC, Elliot RL, Head JF. Vaccination with a mixed vaccine of autogenous and allogeneic breast cancer cells and tumor associated antigens CA153, CEA and CA125-results in immune and clinical responses in breast cancer patients. Cancer Biother. Radiopharm. 2000;15:495-505.

19. Fan NJ, Gao CF, Zhao G, Wang XL, Liu QY. Serum peptidome patterns of breast cancer based on magnetic bead separation and mass spectrometry analysis. Diagn Pathol. 2012;20:45.

20. Ebeling FG, Stieber P, Untch M, Nagel D, Konecny GE, Schmitt UM, Fateh-
Moghadam A, Seidel D. Serum CEA and CA 15-3 as prognostic factors in primary breast cancer; 1Institute of Clinical Chemistry, Klinikum Grosshadern, LudwigMaximilians-University Munich, Germany; 2Department of Obstetrics and Gynecology, Klinikum Grosshadern, Ludwig-Maximilians-University Munich, Germany; British Journal of Cancer. 2002;86:1217-1222.

21. Dhafir Al-azawi, Gabrielle Kelly, Eddie Myers, Enda W. McDermott, Arnold DK Hill, Michael J. Duffy, Niall O. Higgins. BMC Cancer Research article CA 15-3 is predictive of response and disease recurrence following treatment in locally advanced breast cancer. BMC Cancer 2006;6:220.

DOI: $10.1186 / 1471-2407-6-220$

22. Kurebayashi J, Nishimura R, Tanaka K, Kohno N, Kurosumi M, Moriya T, Ogawa Y, Taguchi T. Significance of serum tumour markers in monitoring advanced breast cancer patients treated with systemic therapy: A prospective study. Breast Cancer. 2004;11(4):389-95.

23. Duffy MJ. Serum tumour markers in breast cancer: Are they of clinical value? Clinical Chemistry. 2006;52(3):345-351.

24. Martinez-Trufero J, de Lobera AR, Lao J, Puertolas T, Artal-Cortes A, Zorrilla M, Alonso V, Pazo R, Valero MI, Rios-Mitchell MJ, Calderero V, Herrero A, Anton A. Serum markers and prognosis in locally advanced breast cancer. Tumori. 2005; 91(6):522-30 .

25. Diamindis Fleisher $M$, Dnistrian AM, Sturgeon CM, Lamerz R, Wittliff J. Practice guidelines and recommendations for use of tumor markers in the clinic. In Tumor markers, physiology, pathobiology, technology and clinical applications Edited by: Diamindis EP, Fritsche $\mathrm{H}$, Scharwtz MK, Chan DW. Chicago: AACC Press. 2002;33-63.

26. Hayward JL, Carbone PP, Heuson J-C, Kumaoka S, Segaloff A, Rubens RD. Assessment of response to therapy in advanced breast cancer. Eur $\mathrm{J}$ Cancer. 1997;13:89-94.

27. Anonymous: Clinical practice guidelines for the use of tumor markers in breast and colorectal cancer. Adopted on May 17, 1996 by the American Society of Clinical Oncology. J Clin Oncol. 1996;14:2843-77.

28. INCA/MS, Estimativa 2010, Incidencia de Cancer no Brasil; 2011. 
29. Cancer Genome Atlas Network. Comprehensive molecular portraits of human breast tumors. Nature. 2012; 490(7418):61-70.

30. INCA/RJ, Estimativa 2012, Incid^encia de Cancer no Brasil; 2011.

31. Perkins EA, Small BJ, Balducci $L$, et al. Individual differences in well-being in older breast cancer survivors. Crit Rev Oncol/Hematol. 2007;62:74-83.

32. Balducci L, Beghe C, Parker M, Chausmer A. Prognostic evaluation in geriatric oncology: Problems and perspectives. Archives of Gerontology and Geriatrics. 2005;3:31-41.

33. Birsen Yücel, Seher Bahar, Turgut Kaçan, Metin Şeker M, Gürol Celasun M, Aykut Bahçeci, Nalan Akgül Babacan. Importance of metastasis site in survival of patients with breast cancer. Austin Journal of Medical Oncology. 2014;1(2).

34. Thathiah A, Carson DD. MT1-MMP mediates MUC1 shedding independent of TACE/ADAM17. Biochemical Journal. 2004;382(1):363-373.

35. Hattrup CL, Gendler SJ. Structure and function of the cell surface (tethered) mucins. Annual Review of Physiology. 2008;70:431-457.

36. Duffy MJ, Shering S, Sherry F, McDermott E, O'Higgins N. CA 15-3: A prognostic marker in breast cancer. International Journal of Biological Markers. 2000;15(4): 330-333.

37. Sandri MT, Salvatici M, Botteri $E$, et al. Prognostic role of CA15.3 in 7942 patients with operable breast cancer. Breast Cancer Research and Treatment. 2012;132(1):317-326.

38. Mumtaz Begum, Sajjad Karim, Arif Malik, Rukhshan Khurshid, Muhammad Asif, Asmat Salim, Saeed Ahmed Nagra, Ahmad Zaheer, Zafar lqbal, Adel Mohammed Abuzenadah, Mohammed Hussain Alqahtani, Mahmood Rasool. CA 15-3 (Mucin-1) and physiological characteristics of breast cancer from Lahore, Pakistan. Asian Pacific Journal of Cancer Prevention. 2012;13:5259.

39. Kurebayashi J, Nishimura R, Tanaka K, Kohno N, Kurosumi M, Moriya T, Ogawa $\mathrm{Y}$, Taguchi T. Significance of serum tumour markers in monitoring advanced breast cancer patients treated with systemic therapy: A prospective study. Breast Cancer. 2004;11(4):389-95.
40. Dhafir Al-azawi, Gabrielle Kelly, Eddie Myers, Enda W. McDermott, Arnold DK. Hill, Michael J. Duffy, Niall O. Higgins. CA $15-3$ is predictive of response and disease recurrence following treatment in locally advanced breast cancer. BMC Cancer. 2006;6:220.

41. Liu MT, Huang WT, Wang AY, Huang CC, Huang CY. Prediction of outcome of patients with metastatic breast cancer: Evaluation with prognostic factors and Nottingham prognostic index. Support Care Cancer 2010;18:1553-1564. Pierga JY, Hajage D, Bachelot T, Delaloge $S$, Brain E, et al. High independent prognostic and predictive value of circulating tumor cells compared with serum tumor markers in a large prospective trial in first-line chemotherapy for metastatic breast cancer patients. Ann Oncol. 2012;23:618-624.

42. Kokko R, Holli K, Hakama M. Ca 15-3 in the follow-up of localised breast cancer a prospective study. 2002;38(9):1189-1193.

43. Berruti A, Tampellini M, Torta M, Buniva T, Gorzegno G, Dogliotti L. Prognostic value in predicting overall survival of two mucinous markers: CA 15-3 and CA 125 in breast cancer patients at first relapse of disease. European Journal of Cancer. 1994;30(14):2082-2084.

44. Lin NU, et al. International guidelines for management of metastatic breast cancer (MBC) from the European School of Oncology (ESO)-MBC task force: Surveillance, staging, and evaluation of patients with early-stage and metastatic breast cancer. Breast. 2013;22:203-210.

45. Tumeh SS, Beadle G, Kaplan WD. Clinical significance of solitary rib lesions in patients with extraskeletal malignancy. J Nucl Med. 1985;26:1140-1143.

46. Jacobson AF, et al. Association between number and sites of new bone scan abnormalities and presence of skeletal metastases in patients with breast cancer. J Nucl Med. 1990;31:387-392.

47. Baxter AD, Coakley FV, Finlay DB, West C. The aetiology of solitary hot spots in the ribs on planar bone scans. Nucl Med Commun. 1995;16:834-837.

48. Wu PS, Chiu NT, Lee BF, Yao WJ, Hh WC. Clinical significance of solitary rib hot spots on bone scans in patients with extraskeletal cancer: Correlation with other clinical manifestations. Clin Nucl Med. 2002;27:567-571. 
49. Jacobson AF, Cronin EB, Stomper PC, Kaplan WD. Bone scans with one or two new abnormalities in cancer patients with no known metastases: frequency and serial scintigraphic behavior of benign and malignant lesions. Radiology. 1990;175: 229-232.

50. Citrin DL, Tormey DC, Carbone PP. Implications of the $99 \mathrm{mTc}$ diphosphonate bone scan on treatment of primary breast cancer. Cancer Treat Rep. 1977;61:12491252.

51. Fon GT, Wong WS, Gold RH, Kaiser LR. Skeletal metastases of melanoma: Radiographic, scintigraphic, and clinical review. AJR Am J Roentgenol. 1981;137:103-108.

52. Galasko CS, Doyle FH. The detection of skeletal metastases from mammary cancer: A regional comparison between radiology and scintigraphy. Clin Radiol. 1972;23:295-297.

53. Hage WD, Aboulafia AJ, Aboulafia DM. Incidence, location, and diagnostic evaluation of metastatic bone disease. Orthop Clin North Am. 2000;31:515528.

54. Palmer E, Henrikson B, McKusick K, Strauss HW, Hochberg F. Pain as an indicator of bone metastasis. Acta Radiol. 1988;29:445-449.

55. Bibbo C, Patel DV, Benevenia J. Perioperative considerations in patients with metastatic bone disease. Orthop Clin North Am. 2000;31:577-595.

56. Charito Love, Anabella S. Din, Maria B. Tomas, Tomy P. Kalapparambath, Christopher J. Palestro. Radionuclide bone imaging: An illustrative review. RadioGraphics. 2003;23:341-358.

(c) 2016 Fatima et al.; This is an Open Access article distributed under the terms of the Creative Commons Attribution License (http://creativecommons.org/licenses/by/4.0), which permits unrestricted use, distribution, and reproduction in any medium, provided the original work is properly cited.

Peer-review history:

The peer review history for this paper can be accessed here: http://sciencedomain.org/review-history/16607 